\title{
HUBUNGAN MEKANISME KOPING DENGAN STRES KERJA PERAWAT IGD DAN ICU DI RSUD ULIN BANJARMASIN
}

\author{
Yeni Mulyani ${ }^{1}$, Evi Risa M., Littia Ulfah \\ Email : ${ }^{1}$ yenikep772@gmail.com \\ Poltekkes Kemenkes Banjarmasin
}

\begin{abstract}
The emergency department and intensive care unit is one of central service in hospital and also the part of hospitals that requires skill and educated nurses in providing health services to patients. The demands that must be fulfilled by nurses, both critical care nurses and emergency nurses can cause distress and can become the source of stressor for nurses. If the nurses have no effective coping it will cause working stress. This study aimed to determine the the relationship between coping mechanism with working stress among emergency and critical care nurses in Ulin Banjarmasin Hospital.

This is a quantitative research, with correlative study design. The population of this study were emergency and critical nurses as many as 67 respondents using the total sampling technique obtained 62 respondents who are willing to be respondents. The results were analyzed by Chi-Square test.

The results showed that most nurses had minor working stress with adaptive coping mechanism as many as 43 respondents $(72,9 \%)$. The Chi-Square test results show probability value of 0.026 is smaller than the significance level used 5\% $(0.026$ $<0.05)$, so it can be concluded that there is a relationship between coping mechanism with working stress of emergency and critical nurses in Ulin Banjarmasin Hospital. It is known that most respondents who have maladaptive coping will tend to experience more severe stress.

Therefore, researchers suggest the nurses to perform a reducing stresss activity either relaxation techniques, recreation, or exercise. Increase the knowledge either through education or skills upgrading through specialized training. Suggestion for hospital organization to do assessment on work load and arrangement of nurse amount with nurse competence in emergency and ICU so that it can decrease excessive work load and decrease nurse work stress level and hold special education and training program as needed and demand of work in the ward periodically.
\end{abstract}

Keywords : Nurse, Coping Mechanism, Working Stress 


\section{PENDAHULUAN}

Salah satu pelayanan yang sentral di rumah sakit adalah pelayanan ICU dan IGD.ICU dan IGD merupakan bagian rumah sakit yang membutuhkan perawat yang terampil dan terdidik dalam memberikan pelayanan kesehatan terhadap pasien.

Banyaknya tuntutan kerja dan pelayanan yang bersifat segera dapat membuat perawat IGD rentan mengalami stres kerja (Mutafidz \& Musikasari, 2013)

Sedangkan ICUsendiri adalah suatu bagian dari rumah sakit yang terpisah, dengan staf yang khusus dan perlengkapan yang khusus yang ditujukan untuk observasi, perawatan dan terapi pasien - pasien yang menderita penyakit, cedera atau penyulit - penyulit yang mengancam jiwa atau potensial mengancam jiwa dengan prognosis dubia (Yusminar, 2012)

Tuntutan-tuntutan yang harus dipenuhi oleh perawat baik perawat ICU maupun perawat IGD dapat menimbulkan rasa tertekan dan menjadi sumber stressor bagi perawat. Apabila perawat tidak memiliki koping yang efektif dalam bekerja akan menyebabkan stres kerja.
Mekanisme koping adalah cara yangdilakukan individu dalam menyelesaikan masalah, menyesuaikan diri dengan perubahan, respon terhadap situasi yang mengancam. (Keliat, 2010). Sedangkan Lynda Juall Carpenito mendefinisikan mekanisme koping sebagai kemampuan individu untuk mengatasi stressor internal maupun eksternal secara adekuat yang berhubungan dengan adekuatnya sumbersumber fisik, psikologis, perilaku dan atau kognitif (Kurnia, 2010)

Stres adalah respon tubuh yang tidak spesifik terhadap setiap kebutuhan tubuh yang terganggu, suatu fenomena universalyang terjadi dalam kehidupan sehari hari dan tidak dapat dihindari, setiap orang memahaminya, stres memberi dampak secara total pada individu yaitu terhadap fisik, psikologis, intelektual, sosial dan spiritual, stres dapat mengancam keseimbangan fisiologis. Stres emosi dapat menimbulkan perasaan negatif atau destruktif terhadap diri sendiri dan orang lain. Stres intelektual akan mengganggu persepsi dan kemampuan seseorang dalam menyelesaikan masalah, stres sosial akan mengganggu hubungan 
individu terhadap kehidupan (Rasmun, 2014)

$$
\text { Ketidakmampuan dalam }
$$
menanggung jawabkan tuntutan tersebut sangat mungkin menjadi pemicu timbulnya stres kerja.Stres kerja adalah suatu keadaan dimana seseorang menghadapi tugas atau pekerjaan yang tidak bisa atau belum bisa dijangkau oleh kemampuannya (Arizona, 2008)

Menurut dari hasil penelitian terdahulu tentang mekanisme koping perawat didapatkan bahwa responden mempunyai koping positif terhadap stressor kerja yaitu (97\%). Koping yang berfokus pada masalah secara umum dari hasil penelitian di dapatkan bahwa perawat yang menunjukan koping positif yaitu (100\%). Hal ini disebabkan karena perawat mengganggap stressor wajar atau rendah. Dan secara psikologis perawat mengangap masalah mudah diselesaikan, karena pendidikan perawat yang sudah tinggi serta pengalaman yang banyak. Koping yang berfokus pada emosi dari hasil penelitian didapatkan bahwa koping perawat menunjukan positif yaitu (100\%) (Moebin MF \& Noer Aini, 2012).

Menurut survey di Amerika oleh American Psychological Association
(APA) tahun 2012. Banyak orang Amerika terus melaporkan stres kerja kronis, dengan dua dari lima (41\%) karyawan melaporkan bahwa mereka biasanya merasa tegang atau stres selama bekerja. Penyebab sering dikutip dari stres kerja meliputi gaji rendah (46\%), kurangnya kesempatan untuk pertumbuhan atau kemajuan (41 \%), terlalu berat beban kerja (41\%), jam kerja yang panjang (37\%) dan harapan pekerjaan yang tidak jelas (35\%) (APA. 2012) Menurut survey di beberapa wilayah, Sebesar $45 \%$ perawat Instalasi Gawat darurat di RSUD Pasar Rebo (Yana 2014), 66,7\% perawat di ICU RS Kanker Dharmis (Jusnimar 2012),mengalami stres kerja dengan penyebab yang beragam (Dewi, 2014).

Berdasarkan fakta dan fenomena tersebut, banyaknya tuntutan kerja yang dialami perawat IGD dan ICU sehingga memiliki stres yang tinggi. Melalui mekanisme koping, diasumsikan seorang perawat kemungkinan bisa mengelola masalah yang dihadapi. Maka peneliti tertarik untuk mengetahui "Hubungan Antara Mekanisme Koping dengan Stres Perawat IGD dan ICU Di RSUD Ulin Banjarmasin” agar bisa mencegah / 
mengurangi stres kerja dengan mekanisme koping yang baik.

Rumusan masalah dalam penelitian ini adalah “ Apakah ada hubungan Antara Mekanisme Koping dengan Stres Kerja Perawat IGD dan ICU Di RSUD Ulin Banjarmasin.

\section{METODE PENELITIAN}

Penelitian ini adalah penelitian kuantitatif, dengan jenis penelitian correlative studyyaitu dilakukan dengan cara menghubungkan diantara beberapa variabel, sehingga diketahui ada tidaknya hubungan antara variabel dependen dan independen.

Populasi dalam penelitian ini adalah perawat pelaksana yang bekerja di ruang IGD dan ICU RSUD Ulin Banjarmasin berjumlah 67 perawat, di ruang IGD 33 perawat pelaksana dan ICU 34 perawat pelaksana. Pengambilan sampel pada penelitian ini menggunakan metode nonprobability sampling, yaitu Total sampling,Sampel yang diambil sebanyak 67 orang.

Pengumpulan data dilakukan secara primer dan sekunder.data primer diperoleh dari hasil kuesioner yang telah diberikan mengenai mekanisme koping dan stres kerja perawat IGD dan ICU di
RSUD Ulin Banjarmasin.Data sekunder diperoleh dari data rekap di IGD dan ICU RSUD Ulin Banjarmasin.

Analisa data yaitu analisa univariat dan analisa bivariat menggunakan uji Chi-Square, degan tingkat kemaknaan $(\alpha)=0,05$.

\section{HASIL PENELITIAN}

\section{A. Karakteristik Responden}

a. Karakteristik Responden

Berdasarkan Umur

Karateristik responden

berdasarkan umur dewasa awal dan dewasa tengah, disajikan pada tabel 5.1 berikut:

Tabel 5.1 Distribusi Frekuensi Karakteristik Responden Berdasarkan Umur Perawat IGD dan ICU RSUD Ulin Banjarmasin tahun 2017

\begin{tabular}{cccc}
\hline No. & Batasan Umur & $\mathbf{f}$ & $\%$ \\
\hline 1. & $20-30$ tahun & 29 & 46,8 \\
& (Dewasa awal) & & \\
2. & $>30-65$ tahun & 33 & 53,2 \\
& $\begin{array}{c}\text { (Dewasa tengah) } \\
\text { Jumlah }\end{array}$ & 62 & 100 \\
\hline
\end{tabular}

Berdasarkan tabel 5.1 diatas, dari 62 responden yang diteliti menunjukkan bahwa sebagian besar berumur $>30-65$ tahun (dewasa tengah) yaitu sebanyak 33 orang $(53,2 \%)$. 
b. Karakteristik Responden Berdasarkan Jenis Kelamin Karateristik responden berdasarkan jenis kelamin disajikan pada tabel 5.2 berikut:

Tabel 5.2 Distribusi Frekuensi Karakteristik Responden Berdasarkan Jenis Kelamin Perawat IGD dan ICU di RSUD Ulin Banjarmasin tahun 2017

\begin{tabular}{cccc}
\hline No. & Jenis Kelamin & f & \% \\
\hline 1. & Laki-laki & 32 & 51,6 \\
2. & Perempuan & 30 & 48,4 \\
& Jumlah & 62 & 100 \\
\hline
\end{tabular}

Berdasarkan tabel 5.2, dari 62 responden yang diteliti menunjukkan bahwa sebagian besar responden berjenis kelamin laki-laki sebanyak 32 orang $(51,6 \%)$.

c. Karakteristik Responden Berdasarkan Pendidikan Karateristik responden berdasarkan Pendidikan disajikan pada tabel 5.3 berikut:
Tabel 5.3 Distribusi Frekuensi Karakteristik Responden Berdasarkan Pendidikan Perawat IGD dan ICU di RSUD Ulin Banjarmasin tahun 2017

\begin{tabular}{cccc}
\hline No. & Pendidikan & f & \% \\
\hline 1. & D III Keperawatan & 37 & 59,7 \\
2. & D IV Keperawatan & 4 & 6,5 \\
3. & S1 Keperawatan & 21 & 33,9 \\
& Jumlah & 62 & 100 \\
\hline
\end{tabular}

Berdasarkan tabel 5.3 diatas, dari 62 responden yang diteliti menunjukkan bahwa sebagian besar responden berpendidikan D III Keperawatan yaitu sebanyak 37 orang $(59,7 \%)$.

d. Karakteristik Responden Berdasarkan Lama Kerja

Karateristik responden berdasarkan Lama Kerja disajikan pada tabel 5.4 berikut:

Tabel 5.4 Distribusi Frekuensi Karakteristik Responden Berdasarkan Lama Kerja Perawat IGD dan ICU di RSUD Ulin Banjarmasin tahun 2017

\begin{tabular}{cccc}
\hline No. & Lama Kerja & f & \% \\
\hline 1. & $1-7$ Tahun & 45 & 72,6 \\
2. & $8-14$ Tahun & 17 & 27,4 \\
& Jumlah & 62 & 100 \\
\hline
\end{tabular}


Berdasarkan tabel 5.4 diatas, dari 62 responden yang diteliti menunjukkan bahwa sebagian besar responden dengan lama kerja 1 - 7 Tahun yaitu sebanyak 45 orang $(72,6 \%)$.

\section{B. Hasil Penelitian Hubungan Mekanisme Koping dengan Stres Kerja Perawat IGD dan ICU di RSUD Ulin Banjarmasin}

\section{Analisis Univariat}

\section{a. Mekanisme Koping Perawat IGD dan ICU}

Hasil kuesioner penelitian terhadap mekanisme koping disajikan pada tabel 5.5 dan hasil penelitian stres kerja disajikan pada tabel 5.6 berikut:

Tabel 5.5 Distribusi Frekuensi Mekanisme Koping Perawat di RSUD Ulin Banjarmasin tahun 2017

\begin{tabular}{cccc}
\hline No. & $\begin{array}{c}\text { Mekanisme } \\
\text { Koping }\end{array}$ & f & \% \\
\hline 1. & Adaptif & 59 & 95,5 \\
2. & Maladaptif & 3 & 4,8 \\
& Jumlah & 62 & 100 \\
\hline
\end{tabular}

Berdasarkan tabel 5.5, dari 62 responden yang diteliti terlihat bahwa responden yang kategori mekanisme koping terbanyak yaitu kategori Adaptif sebanyak 59 orang $(95,5 \%)$ dan paling sedikit kategori Maladaptif sebanyak 3 orang $(4,5 \%)$.

\section{b. Stres Kerja Perawat IGD dan} ICU

Tabel 5.6 Distribusi Frekuensi Stres Kerja Perawat di RSUD Ulin Banjarmasin tahun 2017

\begin{tabular}{cccc}
\hline No. & Stres Kerja & f & \% \\
\hline 1. & Ringan & 43 & 69,4 \\
2. & Sedang & 19 & 30,6 \\
& Jumlah & 62 & 100 \\
\hline
\end{tabular}

Berdasarkan tabel 5.6, dari 62 responden yang diteliti terlihat bahwa responden yang kategori Stres Kerja terbanyak yaitu kategori Ringan sebanyak 43 orang $(69,4 \%)$ dan paling sedikit kategori Sedang sebanyak 19 orang $(30,6 \%)$.

\section{Analisis Bivariat}

Berdasarkan hasil hubungan antara mekanisme koping dengan stres kerja perawat IGD dan ICU di RSUD Ulin Banjarmasin didapatkan hasil yang disajikan peneliti pada gambar 5.1 berikut: 
Gambar 5.1 Distribusi Frekuensi Mekanisme Koping dengan Stres Kerja Perawat di RSUD

Ulin Banjarmasin tahun 2017

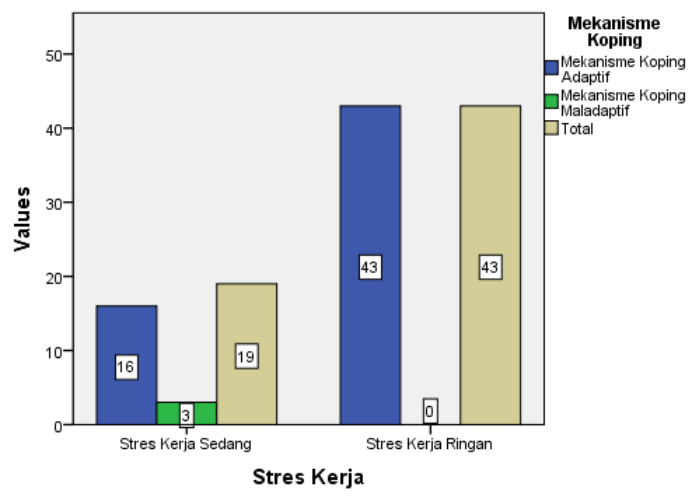

Berdasarkan gambar 5.1, dari 62 responden yang diteliti terlihat bahwa jumlah responden yang terbanyak pada Mekanisme Koping kategori Adaptif dengan Stres Kerja Ringan sebanyak 43 orang $(72,9 \%)$.

\section{PEMBAHASAN}

\section{A. Mekanisme Koping Perawat IGD dan ICU di RSUD Ulin \\ Banjarmasin}

Hasil penelitian yang dilakukan pada 62 responden di RSUD Ulin Banjarmasin menunjukkan bahwa responden yang mekanisme koping adaptif yaitu sebanyak 59 orang $(95,5 \%)$ dan mekanisme koping maladaptif yaitu sebanyak 3 (4,8\%). Hal ini sejalan dengan hasil penelitian Mubin (2004) didapatkan bahwa responden mempunyai koping positif terhadap stressor kerja yaitu 97\% (Moebin MF \& Noer Aini, 2004)

Sebagian besar responden memiliki mekanisme koping adaptif. Mereka sangat setuju pada pernyataan tentang berusaha mendekatkan diri kepada Tuhan dalam menghadapi masalah pekerjaan, itu salah satu strategi koping yang berfokus pada emosi.

Hasil mekanisme koping yang adaptif yaitu sebanyak 59 orang $(59,5 \%)$ dapat dipengaruhi oleh lama kerja. Responden terbanyak yang memiliki mekanisme koping yang adaptif dengan lama kerja 8-14 tahun yaitu 17 orang. Semakin lama responden bekerja, maka semakin ringan tingkat stres kerja yang dialaminya dan semakin sedikit lama bekerja semakin meningkat pula tingkat stres kerjanya. Hal ini sejalan dengan penelitian dari De weerdt 1988 (dalam Mubin 2004) mengatakan ada pengaruh yang kuat dari tingkat lamanya pengalaman dan tingkat pendidikan terhadap kemampuan untuk mengatur emosi (Moebin MF \& Noer Aini, 2004).

Hasil mekanime koping yang maladaptif yaitu sebanyak 3 orang $(4,8 \%)$ dapat dipengaruhi oleh pendidikan. Responden terbanyak yang memiliki mekanisme koping maladaptif 
dengan pendidikan D III dalam penelitian ini sebanyak 3 orang.

Hal ini dikarenakan tingkat pengetahuan atau pendidikan semakin tinggi maka individu mudah untuk mencari informasi (Saragih, 2008). Karena mudahnya mencari informasi maka akan semakin mudah beradaptasi terhadap stressor yang didapat ketika dalam situasi yang dihadapi ketika bekerja.

Dari hasil pernyataan kuesioner yang membahas tentang perlukah melanjutkan pendidikan untuk meningkatkan pengetahuan dan keterampilan bekerja. Dari keseluruhan pernyataan, pernyataan ini yang paling banyak mendapat jawaban tidak setuju. Peneliti berasumsi bahwa banyak yang berpikiran untuk meningkatkan keterampilan dan pengetahuan juga bisa tanpa melanjutkan pendidikan. Keterampilan dan pengetahuan bisa diperoleh di lapangan saat bekerja.

Pendidikan merupakan pengalaman seseorang dalam mengembangkan kemampuan dan meningkatkan intelektualitas, yang artinya semakin tinggi tingkat pendidikan maka semakin tinggi tingkat pengetahuan dan keahlian (Roesmin, 2001).

\section{B. Stres Kerja Perawat IGD dan ICU di RSUD Ulin Banjarmasin}

Hasil penelitian yang dilakukan pada 62 responden di RSUD Ulin Banjarmasin menunjukkan bahwa sebagian besar responden mengalami stres kerja dengan kategori ringan yaitu sebanyak $43(69,4 \%)$ responden dan stres kerja dengan kategori sedang sebanyak $19(30,6 \%)$ responden.

Pada hasil penelitian Mustafidz (2013), menunjukan bahwa responden yang memiliki stres kerja dengan kategori rendah yaitu sebanyak 13 $(61,9 \%)$ responden dan stres kerja dengan kategori tinggi yaitu sebanyak 8 $(38,1 \%)$ responden (Mustafidz, 2013). Hal ini sejalan dengan penelitian Mutmainah (2012), menunjukkan bahwa sebagian basar responden memiliki stres kerja yang ringan yaitu sebanyak 17 (60.7\%) responden dan Stres kerja sedang yaitu sebanyak $11 \quad(39,3 \%)$ responden (Moetmainah, 2012)

Sebagian besar responden memiliki stres kerja ringan, Stressor yang dihadapi setiap orang secara teratur, seperti terlalu banyak tidur, kemacetan lalu lintas, kritikan dari 
atasan. Situasi ini biasanya berlangsung beberapa menit atau jam. Situasi stres ringan biasanya tidak mengakibatkan kerusakan fisiologis kronis (Potter, 2005)

Dari hasil pernyataan kuesioner yang membahas tentang tidak merasakan nyeri di bagian punggung saat bekerja di rumah sakit. Dari keseluruhan pernyataan, pernyataan ini yang paling banyak mendapat jawaban sangat tidak setuju dan tidak setuju.

Hasil stres kerja dengan kategori ringan yaitu sebanyak $43(69,4 \%)$ dapat dipengaruhi oleh usia. Responden yang memiliki stres kerja ringan dengan batasan usia $>30-65$ tahun sebanyak 24 orang. Hal ini sejalan dengan penelitian Jusnimar (2012), menyebutkan bahwa mayoritas perawat mengalami stres kerja ringan pada kelompok umur yang lebih tua $66.7 \%$, disebabkan pada kelompok umur yang lebih tua kemampuan untuk melaksanakan tugas dan beradaptasi dengan lingkungan yang baru lebih mudah. ${ }^{[5]}$ Selain itu semakin bertambahnya umur maka semakin mampu mengendalikan emosi, berpikir rasional, semakin bijaksana, lebih torelan. Terbuka dengan pandangan atau pendapat orang lain, sehingga mampu mengontrol stres yang dialaminya saat bekerja. Hal ini disebabkan karena umur berhubungan erat dengan maturitas atau tingkat kedewasaan. Semakin tua umur seseorang, maka akan semakin meningkat kedewasaannya, kematangan jiwanya, dan lebih mampu dalam melaksanakan tugas dan tanggung jawabnya. ${ }^{[17]}$

\section{Hubungan Mekanisme Koping dengan Stres Kerja Perawat IGD dan ICU di RSUD Ulin Banjarmasin}

Berdasarkan hasil penelitian yang berjumlah 67 orang menggunakan teknik total sampling didapat 62 responden yang bersedia menjadi responden di ruang IGD dan ICU RSUD Ulin Banjarmasin didapatkan hasil pengolahan data yang menggunakan perhitungan korelasi Chi-Square dengan menggunakan aplikasi statistik berbasis komputer SPSS versi 22.0 menunjukkan nilai probabilitas sebesar 0,026 lebih kecil dari nilai taraf signifikasi yang digunakan 5\% $(0,026<0,05)$ sehingga dapat disimpulkan bahwa ada hubungan antara mekanisme koping dengan stres kerja perawat IGD dan ICU di RSUD Ulin Banjarmasin. Berdasarkan tabulasi 
hasil penelitian pada gambar 5.1 dapat diketahui bahwa sebagian besar responden yang memiliki koping yang maladaptif akan cenderung mengalami stres yang lebih berat. Penelitian ini sejalan dengan penelitian Rahmatul (2008) bahwa ada hubungan bermakna antara mekanisme koping dengan stres

Mekanisme koping merupakan proses yang dilalui individu dalam menyesuaikan situasi dalam yang penuh stres (Rasmun, 2004). Ketika perawat dihadapi oleh tuntutan-tuntutan pekerjaan yang menjadi sumber stressor dan menimbulkan rasa tertekan, maka perawat tersebut akan melakukan tindakan untuk menyelesaikan masalah yang di hadapinya untuk menyelesaikan masalah tersebut. Oleh karena itu, cara yang dilakukan individu dalam menyelesaikan masalah, menyesuaikan diri dengan perubahan, respon terhadap situasi yang mengancam disebut dengan mekanisme koping (Saragih, 2008) Apabila koping individu efektif maka bisa menghadapi stressor dengan positif, jika koping tidak efektif makan individu tersebut akan menghadapi stressor dengan maladaptif dan membuat stres menjadi lebih berat.

\section{KESIMPULAN DAN SARAN}

\section{A. Kesimpulan}

1. Sebagian besar mekanisme koping yang digunakan perawat IGD dan ICU di RSUD Ulin Banjarmasin adalah mekanisme koping yang adaptif sebesar $95,5 \%$ yaitu 59 orang.

2. Sebagian besar perawat IGD dan ICU di RSUD Ulin Banjarmasin mengalami stres kerja ringan sebesar 69,4\% yaitu 43 orang.

3. Ada hubungan antara mekanisme koping dengan stres kerja perawat IGD dan ICU di RSUD Ulin Banjarmasin. Jadi, sebagian responden yang memiliki koping yang maladaptif akan cenderung mengalami stres kerja yang lebih berat.

\section{B. Saran}

\section{Perawat}

a. Melakukan aktivitas untuk mengurangi stres baik teknik relaksasi atau refreshing, atau melalui olah raga untuk mengurangi stres sesuai dengan kondisi individu.

b. Meningkatkan pengetahuan baik melalui jenjang pendidikan atau peningkatan 
keterampilan melaui pelatihan khusus.

2. Bagi organisasi rumah sakit

a. Melakukan penilaian terhadap beban kerja dan pengaturan jumlah perawat dengan kompetensi perawat di ruang IGD dan ICU sehingga dapat menurunkan beban kerja yang berlebih dan menurunkan tingkat stres kerja perawat.

b. Mengadakan program pendidikan dan pelatihan khusus sesuai kebutuhan dan tuntutan pekerjaan di ruangan secara berkala.

3. Bagi peneliti selanjutnya

Untuk peneliti selanjutnya hendaknya meneliti faktor-faktor lain yang mempengaruhi stres kerja seperti kematangan emosi, kemajuan teknologi, dan lainlain.

\section{DAFTAR PUSTAKA}

American Psychological Association, 2012. APA Survey Finds Feeling Valued at Work Linked to WellBeing and Performance, http://www.apa.org/news/press/re leases/2012/03/well-being.aspx, diakses tanggal 19 Desember 2016.

Arisona AS, 2008. Hubungan antara Persepsi terhadap Kondisi Lingkungan Kerja dengan Tingkat Stres Kerja pada Karyawan bagian Tebang Angkut di Pabrik Gula Rejo Agung Baru Madiun. Fakultas Psikologi Universitas Muhammadiyah Surakarta, Surakarta. Skripsi.

Dewi Y, 2014. Stres kerja pada perawat Instalasi Gawat Darurat di RSUD Pasar Rebo tahun 2014. Vol. 1 No. 2, Dinas Kesehatan Provinsi DKI Jakarta.

Diklat RS. Haji Jakarta, 2016. Pelatihan ICU Dasar. Jakarta.

Jusnimar, 2012. Gambaran Tingkat Stres Kerja Perawat Intensive Care Unit (ICU) Di Rumah Sakit Kanker Dharmais. Fakultas Ilmu Keperawatan Program Studi Sarjana Depok. Skripsi.

Keliat BA, 1999. Penatalaksanaan Stres, EGC, Jakarta.

Kurnia E, 2010. Pengaruh Mekanisme Koping Terhadap Kekebalan Stres Kerja Pada Karyawan Rumah Sakit Baptis Kediri, Volume 3, Edisi 1, STIKES RS. Baptis, Kediri.

Mubin MF \& Noer'Aini I, 2004. Koping Perawat Terhadap Stress Kerja Di Ruang Rawat Inap Bougenvile Rumah Sakit Telogorejo Semarang Tahun 2004, Jurnal Litbang Universitas Muhamadiyah Semarang. 
Mutafidz \& Mustikasari, 2013. Faktorfaktor Stres Kerja Perawat Di Ruang IGD (Emergency Setting) Di RSUD Cibinong, Universitas Indonesia, Kampus FIK UI, Jawa Barat.

Muthmainah IS, 2012. Faktor-Faktor Penyebab Stress Kerja Di Ruang ICU Pelayanan Jantung Terpadu Dr. Cipto Mangunkusumo Jakarta. Fakultas Ilmu Keperawatan Program Sarjana, Depok. Skripsi.

Potter PA \& Perry AG, 2005. Fundamental Of Nursing : Concept, Process, And Practice, Mosby-Year Book.

Potter PA \& Perry AG, 2010. Buku Ajar Fundamental Keperawatan, EGC, Jakarta.

Rahmatul A, 2008. Hubungan Mekanisme Koping Dengan Stres Pada Pasien Kanker Dalam Mengatasi Efek Samping Kemoterapi Di Ruang Bedah Wanita RSUD M. Djamil. Program Studi Ilmu Keperawatan Fakultas Kedokteran Universitas Andalas, Padang. Skripsi.
Rasmun, 2004. Stres,Koping Dan Adaptasi Teori Dan Pohon Masalah Keperawatan, Sagug Seto, Jakarta.

Rosmawar, 2009. Identifikasi Stres Kerja Dan Strategi Koping Perawat Yang Bertugas Di Ruang IGD RSU Kota Langsa, Fakultas Keperawatan USU Medan. Skripsi.

Saragih H, 2008. Pengaruh Karakteristik Organisasional Dan Individual Terhadap Stres Kerja Perawat Di Ruang Rawat Inap Rumah Sakit Umum Daerah Prosea. Sekolah pascasarjana universitas pascasarjana sumatra utara, Medan. Tesis.

Siagian SP, 2001. Managemen Sumber Daya Manusia. Bumi Aksara, Jakarta.

Silalahi WA. 2014. Mekanisme Koping Pasien Kanker Payudara di RSUP Haji Adam Malik Medan. Fakultas Keperawatan Universitas Sumatra Utara, Medan. Skripsi. 